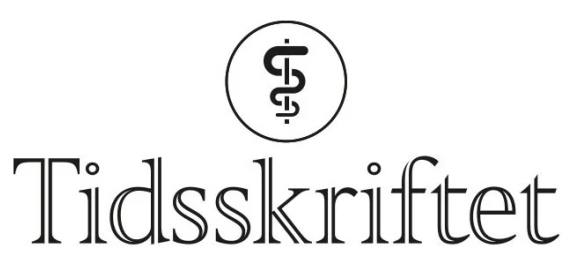

DEN NORSKE LEGEFORENING

\title{
Ikke mere plikt, takk!
}

KRONIKK

\section{KJELL-ARNE HELGEBOSTAD}

kjell-arne.helgebostad@rost.kommune.no

Kjell-Arne Helgebostad er spesialist i allmennmedisin, kommuneoverlege og fastlege i Røst kommune.

Forfatteren har fylt ut ICMJE-skjemaet og oppgir følgende interessekonflikter: Han underviser på grunnkurs i allmennmedisin.

\section{CATO INNERDAL}

Cato Innerdal er spesialist i samfunnsmedisin og kommuneoverlege i Molde kommune. Forfatteren har fylt ut ICMJE-skjemaet og oppgir følgende interessekonflikter: Han er deltidsansatt i Helsedirektoratet og underviser på grunnkurs for allmennleger og på kurs om helserett og førerkortsaker.

Norske leger har taushetsplikt, men også en hel skog av meldeplikter til ulike offentlige instanser. Regelverket kunne trengt en opprydning, men i stedet foreslås det nå enda en meldeplikt. 


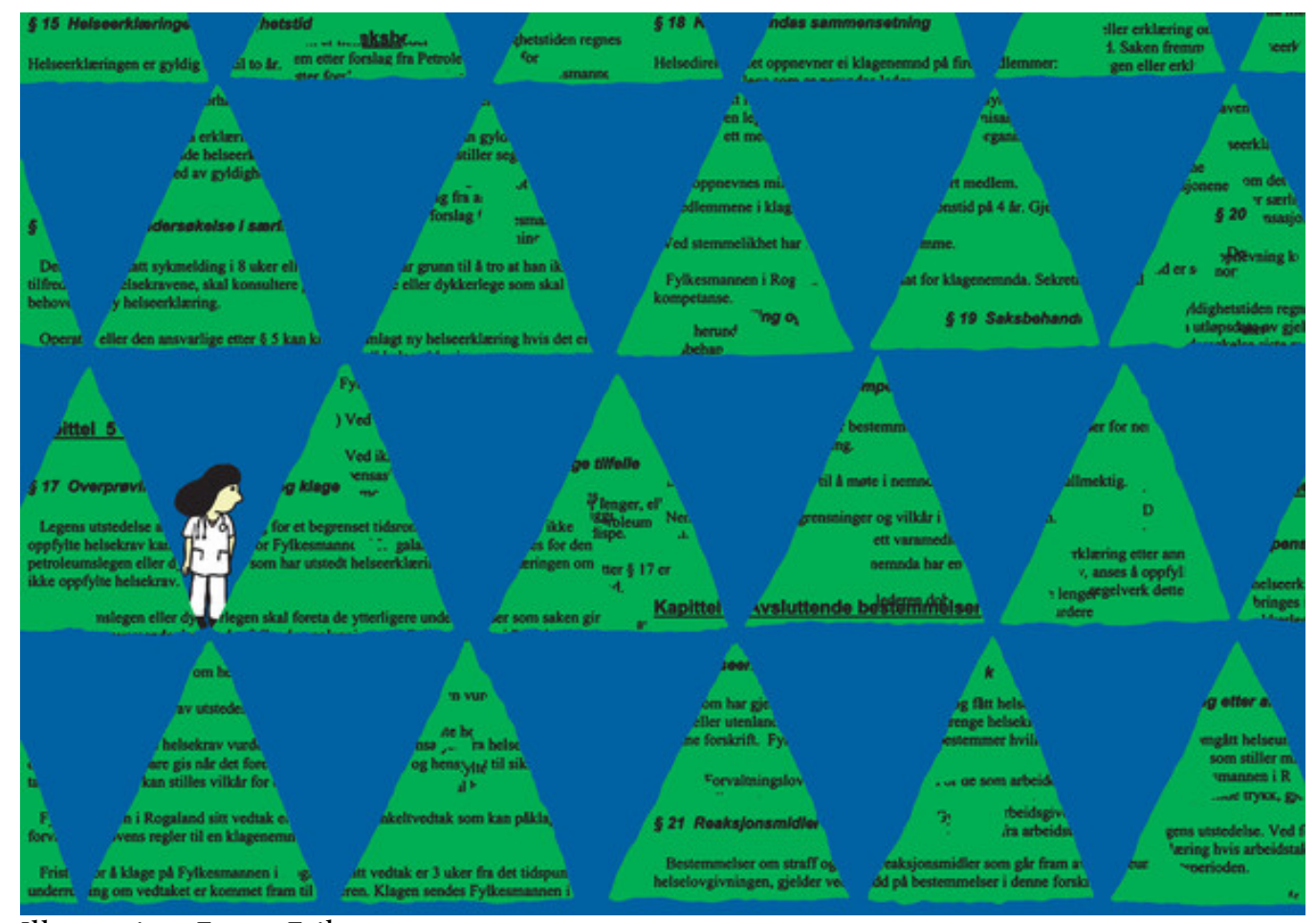

Illustrasjon: Espen Friberg

Taushetsplikten er et viktig grunnprinsipp i helselovgivningen og avgjørende for forholdet mellom lege og pasient. Det finnes imidlertid flere unntaksbestemmelser, og alle leger i Norge har en rekke opplysningsplikter og meldeplikter som setter taushetsplikten til side. Disse bestemmelsene finnes hovedsakelig i helsepersonelloven, men også spredt $\mathrm{i}$ andre lover og forskrifter. Myndighetene har de siste årene gjort endringer i regelverk og gitt føringer for å tydeliggjøre legers meldeplikter. For eksempel er ordlyden endret $\mathrm{i}$ bestemmelsen om meldeplikt til barnevernet (1). Flere endringer er på vei.

Helse- og omsorgsdepartementet fremmet tidligere i år forslag om å endre meldepliktbestemmelsen i helsepersonelloven $\S 34(\underline{2})$. Den nye plikten vil pålegge alle leger, psykologer og optikere å melde fra til Luftfartstilsynet dersom de har en pasient som er flygeleder og ikke oppfyller helsekravene for flygeledere. Intensjonen om å ivareta flysikkerheten er god, men vi mener at denne meldeplikten stiller urealistiske krav til legene. Meldeplikter er viktige, men kan være vanskelige å forholde seg til i hverdagen, særlig når de krever detaljkunnskaper om regelverk som ikke er vanlig lesestoff for leger. To av de mest sentrale meldepliktene er i liten grad omtalt i spesialistforskriftens læringsmål for leger.

\section{Viktig for barnevern og trafikksikkerhet}

Meldeplikten til barnevernet er svært viktig for barna det gjelder, og bør være godt kjent for alt helsepersonell. Dessverre er det ikke slik overalt. En artikkel i Tidsskriftet fra 2019 omtaler flere saker der leger og annet helsepersonell har vært alvorlig bekymret for omsorgssvikt eller vold mot barn uten å melde fra til barnevernet (1).

I tillegg mener vi at alle norske leger må kjenne godt til helsekravene til førerkort og plikten til å informere pasienten og eventuelt fylkesmannen dersom pasienten av helsemessige årsaker ikke skal kjøre bil, slik det framgår av helsepersonelloven § 34 (3). De fleste voksne nordmenn har førerkort, og regelverket er viktig for å ivareta trafikksikkerheten.

Førerkortforskriften gjennomgikk omfattende endringer i 2016 (4).). Helsekravene som da ble innført, er omfattende, og for en rekke medisinske tilstander svært spesifikke. Som eksempel er helsekravene til førerkort i førerkortgruppe 2 og $_{3}$ for pasienter med 
hypertrofisk kardiomyopati angitt i ramme 1. Selv om Helsedirektoratet har publisert en veileder som er tilgjengelig på internett (5), må legene ofte ha inngående kjennskap til slike detaljer i regelverket for å vite når pasienten skal få «kjøreforbud» og når fylkesmannen skal varsles. Dette krever tid, erfaring og kompetanse.

\section{Ramme 1 Eksempel fra førerkortforskriftens vedlegg om helsekrav (5), førerkortgruppe 2 og 3.}

$\S 29$. Helsekrav ved hjertesvikt, klaffesykdommer og kardiomyopatier.

Punkt 14. Hypertrofisk kardiomyopati.

Helsekrav er oppfylt, med mindre det har vært synkope eller to av følgende risikofaktorer er til stede:

a) veggtykkelse mer enn $30 \mathrm{~mm}$

b) ikke-vedvarende VT eller vedvarende (NVST)

c) plutselig død hos førstegradsslektning

d) manglende blodtrykksrespons ved arbeidsbelastning.

Både vegtrafikkloven § $21(\underline{6})$ og førerkortforskriftens helsekrav (5) er tydelige på at det er sjåføren selv som har hovedansvaret, og at ingen skal føre kjøretøy hvis de ikke er i stand til det på en trafikksikker måte. Ved tvil om dette skal lege oppsøkes for undersøkelse. Leger kan imidlertid oppleve situasjoner der pasienter ikke vet eller forstår at de må la bilen stå. Noen ganger er det også slik at pasienten ikke «ønsker å forstå» at de ikke kan kjøre i trafikken. I slike situasjoner er det særlig viktig at legen kjenner meldeplikten.

Pasienter som får beskjed om at de må la bilen stå, kan oppleve det som et stort inngrep i hverdagen, og for noen vil det innebære et yrkesforbud. Fra undervisning på kurs og fra nettfora for allmennleger erfarer vi at leger synes dette kan være utfordrende, både juridisk, medisinsk og mellommenneskelig. Kanskje særlig i kontakten med pasienter som bruker rusmidler, opplever mange leger at meldeplikten kan påvirke den fortrolige relasjonen til pasienten og medføre mye ubehagelig merarbeid (7.).

\section{Hvor er meldepliktene i læringsmålene?}

I læringsmålene for norske legespesialister, som i 2019 ble forskriftsfestet (므), står det påfallende lite om legers meldeplikter. Meldeplikten til barnevernet er nevnt eksplisitt i læringsmål PED-151 for spesialister i pediatri, men i øvrige læringsmål finner vi kun generelle formuleringer av typen «kunnskap om sentrale bestemmelser som regulerer plikter og rettigheter for helsepersonell og pasienter».

«Intensjonen om å ivareta flysikkerheten er god, men meldeplikten stiller urealistiske krav til legene»

Læringsmål ORT-065 angir at spesialister i ortopedi skal «ha kunnskap om tegn på barnemishandling» og "selvstendig kunne undersøke barn der man mistenker barnemishandling». Radiologispesialister skal «ha god kunnskap om radiologisk utredning ved barnemishandling». Meldeplikten til barnevernet er imidlertid ikke nevnt i læringsmålene, verken for ortopeder eller radiologer.

Hva gjelder førerkort, er det stor variasjon i hva som kreves i læringsmålene for de ulike spesialitetene og meldeplikten til fylkesmannen nevnes ikke spesifikt. Sertifikat for luftfartøy er ikke nevnt i noen av læringsmålene.

\section{Ansvar for egen opplæring}


De obligatoriske grunnkursene for allmennleger har en egen nettmodul om «allmennlegen og barnevern» som dekker dette temaet og meldeplikten på en grundig og god måte. Helsekrav til førerkort (og sertifikat for luftfartøy) er imidlertid ikke omtalt i Legeforeningens grunnkurskatalog, der det faglige innholdet i disse kursene er definert (9).

Noen steder har lokale kurskomiteer i Legeforeningen eller fylkesmannen arrangert kurs, men ansvaret for å skaffe seg oversikt over regelverket og meldepliktene er i stor grad overlatt til den enkelte lege. Det er igjen viktig å merke seg at meldepliktene vi har omtalt her, gjelder alle leger, ikke bare spesialister eller fastleger.

Vi registrerer at departementet i sitt høringsnotat nevner at den foreslåtte endringen i meldeplikten kan få konsekvenser for fylkesmenn og andre offentlige instanser. Opplæring av de tusenvis av leger, psykologer og optikere som vil bli pålagt den nye plikten, er imidlertid ikke nevnt (2).

\section{Kompliserte flymedisinske helsekrav}

Flysikkerhet er svært viktig. Ingen bør sette seg bak spakene i et fly eller gå på jobb som flygeleder hvis de ikke er helsemessig skikket til det. Dette burde imidlertid myndighetene kunne sikre på en god nok måte uten altfor spesifikke og omfattende meldeplikter for leger og annet helsepersonell.

Dagens meldeplikt i helsepersonelloven §34 omfatter «lege, psykolog eller optiker som finner at en pasient med førerkort for motorvogn eller sertifikat for luftfartøy ikke oppfyller de helsemessige kravene som stilles» (3). I dette ligger det faktisk et implisitt krav til helsepersonellet: For å kunne vurdere om pasienten oppfyller de helsemessige kravene som stilles, må legen, psykologen og optikeren kjenne til kravene.

Sertifikat for luftfartøy gis i flere klasser, og hver klasse har sine helsekrav. Norge følger et felles europeisk regelverk som definerer de ulike helsekravene til kommersielle piloter (klasse 1), privatflygere (klasse 2) og piloter på lette luftfartøyer (10). For seilflygere, mikroflygere og førere av friballong finnes en egen nasjonal forskrift med egne helsekrav (11).

Det nye forslaget vil altså utvide meldeplikten til også å omfatte flygeledere og de helsekrav som stilles til dem. Helsekravene til flygeledere er fastsatt av European Union Aviation Safety Agency (EASA). De er tilgjengelige på Luftfartstilsynets nettsider i form av et 37 siders dokument på innviklet engelsk (므). Kravene er svært spesifikke og ganske strenge for flere tilstander som forekommer hyppig i befolkningen. De inneholder også flere detaljerte begrensninger på bruk av en rekke vanlige legemidler som hostesaft, tabletter for røykeavvenning og potensmidler.

Helsekravene til flygeledere med supraventrikulære takykardier er gjengitt i ramme 2. Dersom departementets forslag går gjennom, vil for eksempel alle leger få plikt til å sende skriftlig melding til Luftfartstilsynet hvis en pasient som arbeider som flygeleder, får påvist atrieflimmer.

\section{Ramme 2 Eksempel fra helsekrav til flygeledere (12).}

AMC1 ATCO.MED.B.o1o Cardiovascular system

(1) Rhythm and conduction disturbances

(5) Supraventricular arrhythmias

Applicants with significant disturbance of supraventricular rhythm, including sinoatrial dysfunction, whether intermittent or established, should be assessed as unfit. A fit assessment may be considered if cardiological evaluation is satisfactory. 
(i) For initial applicants with atrial fibrillation/flutter, a fit assessment should be limited to those with a single episode of arrhythmia which is considered to be unlikely to recur.

(ii) For revalidation, applicants may be assessed as fit if cardiological evaluation is satisfactory and the stroke risk is sufficiently low. A fit assessment may be considered after a period of stable anticoagulation as prophylaxis, after review by the licensing authority. Anticoagulation should be considered stable if, within the last six months, at least five INR values are documented, of which at least four are within the INR target range. In cases of anticoagulation medication not requiring INR monitoring, a fit assessment may be considered after review by the licensing authority after a period of three months.

(iii) Applicants with asymptomatic sinus pauses up to 2.5 seconds on a resting ECG may be assessed as fit if exercise ECG, 2D echocardiography and 24-hour ambulatory ECG are satisfactory.

(iv) Applicants with symptomatic sino-atrial disease should be assessed as unfit.

«I læeringsmålene for norske legespesialister står det påfallende lite om

legers meldeplikter»

For piloter, flygeledere og enkelte andre yrker innen luftfart kreves gyldig helseattest utstedt av godkjent flylege. I enkelte land er «flylege» en egen legespesialitet. I Norge og andre EU/EØS-land brukes betegnelsen aeromedical examiner (AME) om sivile flyleger som utfører undersøkelser og seleksjonsmedisinske vurderinger av flygende personell og flygeledere. På Luftfartstilsynet nettsider finnes en liste over godkjente norske sivile flyleger (13). Disse legene har vært gjennom flere uker med kursing og opplæring, blant annet i de flymedisinske helsekravene. Mange av dem arbeider også som allmennleger. Forsvaret har ansatt egne militære flyleger.

I dag er det ikke legene, men den enkelte flygeleder som har plikt til å melde fra til luftfartsmyndighetene om forhold som kan ha betydning for om vedkommende oppfyller de medisinske vilkårene for å jobbe som flygeleder. Vi mener det fortsatt bør være slik.

\section{Et villnis av unntak og plikter}

Leger er vant til å vurdere hvordan sykdom, legemiddelbruk og andre medisinske forhold kan påvirke funksjon og arbeidsevne. Vanlig klinisk legearbeid er imidlertid vesensforskjellig fra systematisk seleksjonsundersøkelse. Det er rett og slett ikke realistisk å pålegge alle norske leger å sette seg inn i flere sett med detaljerte helsekrav og spane i hverdagen etter pasienter som ikke oppfyller dem. Og kan det virkelig forventes at leger, optikere og psykologer ved ethvert tilfeldig pasientmøte skal kartlegge om pasienten arbeider som flygeleder eller flyr luftballong på fritiden?

I stedet for meldeplikt knyttet til helsekrav mener vi at helsepersonell burde hatt en generell meldeadgang dersom de får kjennskap til pasienter som av helsemessige grunner åpenbart ikke bør føre luftfartøy, jobbe som flygeledere eller utføre andre yrker der de kan utsette andre for fare. Forslaget fra departementet inneholder faktisk også en meldeadgang, men denne er knyttet til spesifikke sertifikater og inneholder kompliserte formuleringer om blant annet «førerrett for fritidsbåter med skroglengde opptil 24 meter

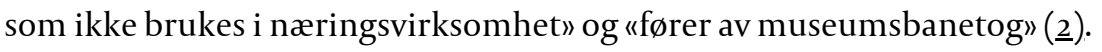

Når skogen av meldeplikter og andre bestemmelser om unntak fra taushetsplikten vokser seg stadig større og tettere, blir det til slutt nærmest umulig for legene å ha nok kunnskap om hver enkelt bestemmelse, og ikke minst å holde oversikt og huske på alle meldepliktene. Myndighetene bør ta inn over seg at taushetsplikten, 
unntaksbestemmelser fra denne og spesielt meldeplikter er et viktig og krevende tema for helsepersonell. Enhver endring i pliktbestemmelser kan få store praktiske konsekvenser for alle dem som blir pålagt å kjenne og følge plikten. Vi mener at opplæring og opprydding i dagens regelverk bør prioriteres framfor å pålegge landets leger enda flere plikter.

\section{LITTERATUR}

1. Homlong L, Fredheim G, Knudsen H. Helsepersonell har plikt til å melde til barnevernet. Tidsskr Nor Legeforen 2019; 139. doi: 10.4045/tidsskr.19.0276. [PubMed][CrossRef]

2. Helse- og omsorgsdepartementet. Høringsnotat: Endring i helsepersonelloven $\S 34$ og ny $\S 34$ a melding ved helsesvekkelse av betydning for trafikksikkerhet.

https://www.regjeringen.no/no/dokumenter/horing-av-forslag-til-endringer-i-helsepersonelloven--34og-ny--34-a---melding-ved-helsesvekkelse-av-betydning-for-trafikksikkerhet/id2686269/ Lest 26.5.2020.

3. LOV-1999-07-02-64. Lov om helsepersonell m.v. (helsepersonelloven). https://lovdata.no/dokument/NL/lov/1999-07-02-64 Lest 26.5.2020.

4. FOR-2004-01-19-298. Forskrift om endring i førerkortforskriften. https://lovdata.no/dokument/LTI/forskrift/2016-o6-13-655 Lest 26.5.2020.

5. Helsedirektoratet. Førerkortveilederen.

https://www.helsedirektoratet.no/veiledere/forerkortveilederen Lest 26.5.2020.

6. LOV-1965-o6-18-4. Lov om vegtrafikk (vegtrafikkloven). https://lovdata.no/dokument/NL/lov/1965o6-18-4 Lest 26.5.2020.

7. Wahl A. Oppskrift på fiendskap. Tidsskr Nor Legeforen 2018; 138. doi:10.4045/tidsskr.18.o756. [CrossRef]

8. FOR-2016-12-08-1482. Forskrift om spesialistutdanning og spesialistgodkjenning for leger og tannleger (spesialistforskriften). Vedlegg 2. Læringsmål for spesialistutdanningen av leger. https://lovdata.no/dokument/SF/forskrift/2016-12-08-1482/KAPITTEL_9\#KAPITTEL_9 Lest 26.5.2020.

9. Revidert utgave av grunnkurskatalog for spesialistutdanningen i allmennmedisin. En veileder for kursarrangører og kurskomiteer. Oslo: Den norske legeforening, 2019. https://www.legeforeningen.no/contentassets/6c685bd6gf8b461489fb33f483ode2bo/grunnkurskatalo g-140319.pdf Lest 26.5.2020.

10. Nyttig informasjon for flyleger og flymedisinsk senter. Versjon 1. Bodø: Luftfartstilsynet, 2017. https://luftfartstilsynet.no/globalassets/dokumenter/flymedisin/nyttig-informasjon-for-flyleger-ogflymedisinsk-senter.pdf Lest 26.5.2020.

11. FOR-2001-o8-23-1068. Forskrift om medisinske krav for seilflygere, mikroflygere, førere av friballong og kabinbesetningsmedlemmer (BSL C 1-3). https://lovdata.no/dokument/SF/forskrift/2oo1o8-23-1068 Lest 26.5.2020.

12. European Aviation Safety Agency. Acceptable Means of Compliance (AMC) and Guidance Material (GM). https://luftfartstilsynet.no/globalassets/dokumenter/flymedisin/medical-requirements-for-airtraffic-controllers.pdf Lest 26.5.2020.

13. Finn en flylege https://luftfartstilsynet.no/aktorer/flymedisin/godkjente-flyleger/ Lest 26.5.2020.

Publisert: 8. oktober 2020. Tidsskr Nor Legeforen. DOI: 10.4045/tidsskr.20.0102

Mottatt 4.2.2020, første revisjon innsendt 24.3.2020, godkjent 26.5.2020.

(C) Tidsskrift for Den norske legeforening 2023. Lastet ned fra tidsskriftet.no 26. april 2023. 